Pulgarín-Arias, A., Bustamante-García, $H$. Zapata-Zuluaga, L. (2019). Noción de interés público en las constituciones de Iberoamérica. Contaduría Universidad de Antioquia, 75, 1342.

Doi: https://doi.org/10.17533/udea.rc.n75a01

\title{
Noción de interés público en las constituciones de lberoamérica*
}

\author{
Andrés-Felipe Pulgarín-Arias \\ andres.pulgarin@udea.edu.co \\ Universidad de Antioquia \\ Orcid: 0000-0003-4646-5957
}

\author{
Hernán-Carlos Bustamante-García \\ bustamantehc@gmail.com \\ Universidad Autónoma Latinoamericana \\ Orcid: 0000-0002-1342-2400
}

Luz-Mery Zapata-Zuluaga

Lmery.zapata@udea.edu.co

Universidad de Antioquia

Orcid: 0000-0002-0842-0363

* Este artículo corresponde a un producto del proyecto de investigación denominado "Contabilidad, control económico e interés público. Una aproximación a su relación en un estado social de derecho” ejecutado en el marco del convenio celebrado entre la Universidad Autónoma Latinoamericana (Convocatoria CONVDI2017-01 - Código de proyecto 27-000028) y la Universidad de Antioquia (Convocatoria - Código de proyecto 2018-19570). Los estudiantes Mónica Liliana Areiza Ruiz, Pedro Pablo Loaiza Londoño y Diego Alejandro David Gaviria fueron alumnos en formación, que aportaron en la metodología y productos para la elaboración del texto. 


\title{
Noción de interés público en las constituciones de Iberoamérica
}

Resumen: Este artículo fue elaborado a partir de un estudio que se ha venido ejecutando en torno al termino interés público en las Constituciones Políticas de Colombia, Argentina, Bolivia, Brasil, Chile, Ecuador, México, Panamá, Paraguay, Perú, Uruguay, Venezuela y España; las cuales fueron seleccionadas por su conexión continental, relación idiomática y cercanía estructural con la Constitución Política colombiana. La metodología empleada para ello fue cualitativa, con análisis y sistematización a través de descriptores así: como se utiliza, como se entiende, como se incorpora, como se indica o se define, carácter de uso otorgado a la expresión y como se enuncian sus usos. El artículo se divide en cuatro apartados: aspectos metodológicos, componente teórico, resultados y conclusiones. Como hallazgo general se puede decir que, tanto el interés público como las expresiones cercanas y complementarias (grupo definido para la clasificación), son utilizados para asignar una característica de importancia social a ciertos bienes, instituciones, actividades; o motivación en la órbita de acción del Estado.

Palabras claves: Interés público, expresiones complementarias, expresiones cercanas, descriptor, Constitución Política.

\section{The notion of public interest in Ibero-American constitutions}

Abstract: This paper was developed from a study carried out around the term public interest through a search on the Political constitutions of Colombia, Argentina, Bolivia, Brazil, Chile, Ecuador, Mexico, Panama, Paraguay, Peru, Uruguay, Venezuela and Spain, which were chosen due to their continental connection, language relation and structural closeness to the Colombian Political Constitution. The methodology used was qualitative with analysis and systematization through descriptors such as: how it is used, how it is understood, how it is incorporated, how it is indicated or defined, what is the nature of the use that is given to the expression and how its uses are enunciated. The paper is divided in three sections: methodological aspects, theoretical component, and results and conclusions. As a general finding it can be said that both public interest and close and complementary expressions (groups defined for classification) are used to assign a characteristic to certain goods, institutions, activities or motivation in the State's orbit of action.

Keywords: Public interest, complementary expressions, close expressions, descriptor, Political Constitution.

\section{La notion d'intérêt public dans les Constitutions de l'Ibéro-Amérique}

Résumé: Cet article est basé sur une étude autour du terme intérêt public et porte sur une recherche dans les Constitutions Politiques de Colombie, Argentine, Bolivie, Brésil, Chili, Équateur, Mexique, Panama, Paraguay, Pérou, Uruguay, Vénézuéla et Espagne. Elles ont été choisies grâce à leur connexion continentale, leur rapport idiomatique et la proximité structurelle avec la Constitution Politique Colombienne. La méthode qualitative a été utilisée avec analyse et systématisation au moyen de descripteurs comme suit : comment le terme est utilisé, comment il est compris, comment il est intégré, comment il est indiqué ou défini, à quoi il octroie le caractère de l'expression et comment ses usages sont énoncés. Cet article comporte trois parties : les aspects méthodologiques, les composants théoriques, les résultats et conclusions. En guise de découverte générale, on peut dire que le terme d'intérêt publique ainsi que les expressions qui lui sont proches ou complémentaires (des groupes définis à classifier) sont utilisés pour donner une caractéristique à certains biens, institutions, activités ou motivations dans le champ d'action de l'État.

Mots-clés: intérêt publique, expressions complémentaires, expressions proches, descripteur, Constitution Politique

\begin{abstract}
A noção de "Interesse Público" nas constituições de Ibero-América
Resumo: Este artigo foi elaborado a partir de um estudo executado em torno ao termo "interesse público". Com uma pesquisa nas Constituições Políticas da Colômbia, Argentina, Bolívia, Brasil, Chile, Equador, México, Panamá, Paraguai, Peru, Uruguai, Venezuela e Espanha, as quais foram escolhidas pela sua conexão continental, relação idiomática e proximidade estrutural com a Constituição Política Colombiana. A metodologia usada para isso foi qualitativa, com análise e sistematização por meio de descritores, assim: como se utiliza, como se entende, como se incorpora, como se define, a que dá o caráter da expressão e como se mencionam os seus usos. $O$ artigo está dividido em três sessões: aspectos metodológicos, componente teórico, resultados y conclusões. Como descobrimento geral, pode se dizer que tanto o interesse público quanto as expressões próximas e complementárias (grupo definido para classificação), são utilizados para assignar uma característica a certos bens, instituições, atividades ou motivação na órbita de ação do Estado.
\end{abstract}

Palavras chave: interesse público, expressões complementárias, expressões próximas, descritor, Constituição Política. 


\title{
Noción de interés público en las constituciones de Iberoamérica
}

\author{
Andrés-Felipe Pulgarín-Arias, Hernán-Carlos Bustamante-García, \\ Luz-Mery Zapata-Zuluaga.
}

Doi: https://doi.org/10.17533/udea.rc.n75a01

Primera versión recibida en septiembre de 2019 - Versión final aceptada en noviembre de 2019

\section{Introducción}

I os resultados esbozados en este artículo, están vinculados a la investigación Ltitulada: "El interés público y su atomización. Bases para fundamentar una tesis en materia de regulación en contabilidad y control" (2019), proyecto en el cual se hallaron múltiples particularidades del interés público y se deja un precedente para la realización de futuros estudios, en especial porque se indagó por la expresión interés público en las Constituciones Políticas de trece países con cercanía en idioma y estructura constitucional y se encontraron expresiones, usos cercanos y otros complementarios. Uno de esos análisis, es precisamente el que se plasmó en los párrafos que se encontrarán a continuación, partiendo del hecho de que, con los resultados de la investigación ya mencionada, se pudo establecer que, el interés público no se ha definido desde la perspectiva normativa constitucional en Colombia ni en los trece países objeto de investigación, razón por la cual dentro de la muestra objeto de análisis se pudieron identificar nueve usos (objetos o materias reguladas) que tiene el interés público en la totalidad de países estudiados, y a su vez, se pudo establecer que no es uniforme el uso por país, dado que en varios se le asocian diversos usos, como en el caso de Colombia del cual se destacaron cinco (Funciones de órganos del Estado, limitación de ciertos derechos como cesión de los intereses individuales, otorgamiento de un orden de interés especial a ciertas actividades económicas, facultad contractual en la celebración de contratos y forma intervencionista).

El uso dispar, tanto de la expresión interés público como de las expresiones cercanas y complementarias, condujo a generar una parametrización de los 
elementos cualitativos comunes incorporados en las Constituciones analizadas, de forma tal que se lograra una aproximación a las acepciones. Debido a que el interés público no es pacífico en su uso, también se puedo establecer que en ocasiones no se utiliza para referenciar una función y por el contrario se utiliza de manera más abstracta aún, lo que lo hace más indeterminado, y en razón a esta indeterminación se generaron elementos característicos o patrones que permitieron identificar cinco categorías con base a una hermenéutica en asociación a los usos que trató de darle el constituyente al momento de utilizar el concepto.

La parametrización ya mencionada se elaboró a partir de cinco descriptores de la expresión: cómo se utiliza, cómo se entiende, cómo se incorpora, cómo se indica o se define, a qué otorga el carácter de la expresión y, por último, cómo se enuncian sus usos, los cuales fueron definidos a partir de un estudio detallado de las Constituciones objeto de estudio.

La estructura del artículo se divide en cuatro apartados principales: el primero es una base teórica; el segundo está relacionado con la metodología cualitativa de análisis y clasificación de expresiones, asociada a una hermenéutica conceptual para llegar a la sistematización de las veinte expresiones en las cartas constitucionales de los trece países Iberoamericanos, atendiendo a cinco descriptores elaborados a partir del contenido constitucional, además de ello, se incluye la definición de los descriptores construidos y utilizados; y el tercero plasma los resultados de la investigación y por último las conclusiones.

\section{Revisión de la literatura}

El interés es un concepto natural en todo actuar humano. Todos podemos tener interés en algo y esos intereses pueden estar vinculados a múltiples matices que cada persona (o grupo) incorpora; tan es así que las pluralidades de intereses generan una tensión cuando los intereses individuales no son compatibles con el interés de otros o los comunes.

Atendiendo a la diversidad de estos, socialmente se van extendiendo, acordes a ciertos momentos históricos, al punto que se podría plantear que van cambiando, no son perennes y en tal sentido, el interés como concepto va cambiando epistemológicamente. A manera de ejemplo, la política y la moral de la antigua Grecia no tenían una distinción muy clara; y con posterioridad, en el renacimiento con Nicolás Maquiavelo, se podría decir que se da inicio a la distinción entre ambas, y con ello también cambian los intereses que se construyen en el tejido social. En ese orden de ideas, podríamos plantear que lo público y lo privado como intereses, son categoría que han ido cambiando, y desde la modernidad su constructo tiene tal impacto que hoy marca directamente los órdenes jurídicos y políticos en atención a los reclamos que 
los factores reales de poder, que, según Hernando Valencia Villa, está definida por factores de poder, que además fijar los fundamentos de las Constituciones, establecen su configuración principal.

Por esta razón, gran parte de esos intereses que marcan los órdenes, están plasmados en las Constituciones como tejedoras de intereses en sentido político y jurídico, los cuales se positivizan para efectivizar los intereses comunes, dado que; si el sentido de estos derechos (intereses) es sólo político, es nadar contra la corriente (Bernal, 2008), porque la eficacia de los derechos depende del derecho positivo y es desde éste último en donde la política entra en sujeción frente al derecho, dado que el trasunto al ámbito jurídico de los bienes (interés público), hace que los matices interpretativos de los intereses tengan sujeción al orden constitucional que está inmerso en un conjunto de valores y principios, como son el interés público, sociales y colectivos. A modo de ejemplo están los derechos colectivos y del medio ambiente, los cuales no se puede abrogar a un interés particular (una persona específica).

Desde esta perspectiva, la positivización del Interés público en la constitución política colombiana, como se verá más adelante, está enmarcada en acepciones económico funcionales, limitantes y contractuales, lo que lo envuelve en un abanico de interpretaciones, en especial por el número de acepciones que tratan de abocar al mismo sentido o principio en una concepción del interés desde una cooperación social y programática.

Las diferencias interpretativas del Interés público por lo indeterminado y equívoco, hace que los puntos de ubicación para su hermenéutica puedan abordarse desde miradas ideológicas, filosóficas, políticas y jurídicas diferentes, visiones que en ocasiones son yuxtapuestas, lo que hace que no sea pacífico su uso, pues como fuente de inspiración constituyente está atravesado por subjetividades, que en todo caso deberán encausarse en el proyecto político constitucional.

La perspectiva económica del interés público es casi inseparable, pues tal como lo plantea Carnelutti, los intereses son en principio económicos, más que jurídicos y se tejen en la escena política, dado que están encaminados en la satisfacción de unas necesidades ilimitadas frente a unos recursos limitados; y es ahí donde el interés público da un orden a ese caos entre el yo y el tú, dado que lo público se basa en los intereses comunes de una sociedad. En este orden de ideas, se podría afirmar que los intereses están en el individuo (sujeto de derechos) en tanto ser social, y lo público es el acuerdo existen para la convivencia pacífica de esos intereses.

Autores, como Antonio Enrique Pérez Luño (2011), basado en un texto de Avelino Manuel Quintas (Analisi del bene comune, 1979) indica que el bien común tiene aspectos éticos, políticos y jurídicos (2011, p. 239) y establece que el concepto está enmarcado en una ambigüiedad terminológica, así como 
sus análogas interés general, interés público, bienestar social etc., y que estas en vez de estar distantes de la filosofía tomista Aristotélica, por el contrario, están atadas y lo que ocurre es la generación de nuevas denominaciones para el concepto antiguo. Incluso plantea que

La confrontación de la idea de bien común con la noción anglosajona del public interest, permite observar que la suposición de un significado estrictamente descriptivo de este término, frente a la dimensión puramente axiológica del bien común no responde a la realidad. Antes bien, es propio de ambas nociones, que en el fondo no son sino distintas formas de aludir a los valores-guía de la convivencia jurídico-política, el manifestarse en un doble plano. (2011 p 239)

Es decir que, podríamos plantear que el concepto propone en términos descriptivos, unas metas sociales (la comunidad) y en términos prescriptivos lo asume como un deber ser (valor del bien común). Es por esto que ambas dimensiones son elemento nodal para que se materialice en un momento histórico la estructura de la sociedad política en donde los intereses públicos y comunes estén acordes a circunstancias históricas, geográficas, sociales y económicas; es decir, este debe surtir los intereses de la Nación a la cual están enmarcados, para al caso colombiano, deben estar dentro del tríptico económico que establece la constitución que son propiedad, empresa y trabajo (Botero, 2011).

El interés público por lo tanto debe procurar los intereses generales y buscar la abdicación del absolutismo eliminando la concentración del poder, característico de la monarquía, para proteger los derechos de libertad, propiedad y seguridad individual. Bajo la fórmula del liberalismo político surgió el concepto de interés público, cimentado en la protección de derechos individualidad toda vez que la clase burguesa era la titular del interés público, el cual se constituyó como el interés común de los burgueses representado en la protección de la propiedad privada y en el establecimiento del derecho privado las interacciones mercantiles y los límites al pleno funcionamiento de los mecanismos de mercado. La esfera pública burguesa se estatuyó en instituciones públicas de mediación política entre el Estado y la sociedad, tales como el parlamento, los partidos y la prensa en las cuales se circunscribía el principio de publicidad, visibilidad de sus actuaciones y apertura a todo aquel que fuera ciudadano, por lo que muchos sectores de la población querían obtener dicho estatus. Por esta razón con el Estado Social se establecieron los derechos sociales o económicos, se contempló un régimen de derechos políticos y se limitaron los derechos individuales reconociéndoles una función social.

En este contexto, la acepción del interés público no es precisa, dado que no hay una clara diferenciación entre público lo y privado. El Estado Social tenía el deber de promover el bienestar general que se gestaba a través del servicio 
público como lo referencia el francés León Duguit al concebirlo como “(...) un instrumento para el logro de la igualdad, la mejora de las condiciones de vida de los ciudadanos (...)" (citado en Rodríguez y Muñoz, 2013, p. 64). Mientras que para, Rebollo (1983) el servicio público tenía una idea oculta "(...) que no era otra que la idea de solidaridad social plasmada en el Estado que debe asumir las necesidades e intereses colectivos (...)" (citado en Rodríguez y Muñoz, 2013, p. 63).

Finalmente, en cuanto a la evolución del concepto interés público se cita a Bourdieu (1997), quien afirma que en el estado neoliberal se hace referencia al interés público al proponer construir un orden social o colectividades que no tengan como único objeto la persecución del interés egoísta, sino la búsqueda racional de fines que hayan sido elaborados y aprobados colectivamente, aún cuando resulte nebuloso frente a la naturaleza del modelo neoliberal, considerado básicamente como "el reino absoluto de la flexibilidad" que es posible gracias a las políticas de desregulación de los mercados, imposición abusiva de valores comerciales y a la destrucción de todas las instancias colectivas que pueden contrarrestar sus efectos, entre ellos el Estado como depositario de lo público.

\section{III.Aspectos metodológicos}

Este trabajo es resultado de una investigación en la que se hicieron varias sistematizaciones y acá se plasman algunos resultados de ésta, en cuanto a los usos que las constituciones de trece países le dan al interés público y a un conjunto de expresiones vinculadas de una u otra forma con este como se explicará más adelante. Como se mencionó, la metodología empleada es cualitativa, con un análisis hermenéutico conceptual y sistematización de algunas expresiones que surgieron como consecuencia de las lecturas hechas a los textos constitucionales, en los que sólo se trataba de caracterizar el interés público, pero a pesar de esto se encontraron fuentes teóricas como: Bobbio (2006), Baker (2009), Correa (2006), De Cores y Cal (2007), Gil (2014), Gómez (2010), Jiménez (2012), López (2010), Múnera (2001), Quinche (2017), Pérez (2011), Stiglitz (2006), además del hecho que, en las mismas Constituciones Políticas traían a colación otras expresiones similares en el contenido, por lo que se hizo necesario ampliar la búsqueda hacia otros usos, dado que en la literatura y en la normatividad objeto de estudio (Constituciones Políticas), se usan estas expresiones, bien en sentido de similitud o de complementariedad. Dichas expresiones son: interés colectivo, interés común, interés de la nación, interés del estado, interés del pueblo, interés general, interés nacional, e interés social, bien colectivo, bien común, bien general, bienestar colectivo, bienestar común, bienestar de la población, bienestar general, bienestar social, utilidad común, utilidad nacional y utilidad pública. 
Los trece países Iberoamericanos son: Colombia, Argentina, Bolivia, Brasil, Chile, Ecuador, México, Panamá, Paraguay, Perú, Uruguay, Venezuela y España, elegidos por su conexión continental, relación idiomática y cercanía estructural de la Constitución Política colombiana. Para profundizar en el último aspecto mencionado, se destaca lo indicado por Medina (2004), autor que plantea varios aspectos relevantes en la jurisdicción de las patrias elegidas para este estudio. Como primera postulación se encuentra que, Latinoamérica acogió dos de las corrientes iusteóricas más destacadas de las tradiciones continentales durante el siglo XX: la escuela cuyos representantes son Gény, Josserand, Ripert y Bonnecase, donde se puso en práctica la investigación científica en el derecho privado sin restricciones y el positivismo solidarista del autor León Duguit, cuyo principal enfoque fue el derecho público. Por otro lado, plantea que la adopción de la teoría de Hans Kelsen, de lo cual indica que ha sido transformador para el proceso evolutivo de la jurídica dentro del continente, partiendo de las interpretaciones y los usos, que fueron variados de acuerdo a cada país. Con lo anterior, se resalta que la historia del derecho dentro de los países elegidos para la elaboración de esta investigación, es similar en cuanto a fundamentos, estructura y al hecho de poseer una gran influencia por los sistemas jurídicos establecidos en otros continentes.

Los cinco (5) descriptores abordan aspectos comunes y diferenciadores que se construyeron a partir de lectura, análisis, síntesis y conceptualización de las cartas constitucionales de los países abordados. A su vez los descriptores se dividen en diferentes usos, arrojando como resultado la siguiente clasificación:

\section{Cuadro 1: Descriptores}

\begin{tabular}{|l|l|}
\hline \multirow{5}{*}{ 1. La expresión se utiliza como: } & a) Principio/valor (entendido principio como criterio o norma moral que guía la conducta) \\
\hline & b) Motivación (en razón a la expresión o por inspiración en ella se efectúa una acción) \\
\hline & c) Limitante (limita la potestad de un derecho en razón a la expresión) \\
\hline & d) Salvedad (excepción que realiza atendiendo a la expresión) \\
\hline & e) Prohibición \\
\hline \multirow{5}{*}{ 2. La expresión se entiende como: } & $\begin{array}{l}\text { a) Deber/ Facultad/ Finalidad del Estado (deber: obligación, responsabilidad, compromiso; } \\
\text { facultad: potestad, atribución, competencia, poder; finalidad: ideal, objetivo, intención, }\end{array}$ \\
\hline & b) Derecho/ Deber ciudadano \\
\hline \multirow{5}{*}{ 3. La expresión incorpora una perspectiva: } & c) Ambos \\
\hline & a) Económica \\
\hline b) No económica \\
\hline c) Ambos \\
\hline carácter de la expresión, ya sea a: & a) Actividades \\
\hline 5. Enuncia usos de la expresión & b) Instituciones / Entidades \\
\hline & c) Bienes \\
\hline
\end{tabular}

Fuente: Elaboración propia. 
El descriptor número uno trata de dar cuenta del sentido en el que es utilizada la expresión, identificándose cinco usos:

a) Principio/valor: Entendido desde la definición de principio que incorpora la Real Academia Española así: "norma o idea fundamental que rige el pensamiento o la conducta" (RAE, s.f.); es decir, que cuando la expresión se usa en el sentido de principio/valor, su uso pretende ser una guío de equilibrio, o virtud de la administración pública para eliminar las expresiones de abstracción del poder y la norma pasa a ser una forma de moralización de la acción de la admiración determinada por la Constitución Política. Ramírez (1999), manifiesta que, los principios constitucionales se dividen en dos grupos: generales y especiales.

Los generales han de ser comprendidos como las normas que toman un rol principal en la integración, creación e interpretación del ordenamiento jurídico, es decir, bajo estos principios se establecen los que han de regir dentro de una rama específica del derecho como el derecho laboral, penal, entro otras, estos que se derivan de las especificidades son los que se conocen como principios especiales; el autor ejemplifica con los principios de buena fe, seguridad jurídica, orden, legalidad, etc. Además de lo anterior, Ramírez (1999) plantea que "los principios permean todo el ordenamiento jurídico, por virtud de sus funciones y porque ellos hacen sistematización y coherencia interna" (pág. 30 ), es decir que, cada una de las normas que rigen dentro de un territorio deben guardar absoluta coherencia con los principios, mas, cuando se trata de los principios constitucionales. Como lo plantea Kelsen, existe una jerarquía normativa que le da supremacía a la Constitución Política, por ende, cualquier norma que se promulgue dentro del territorio, no podrá contrariar a la Constitución y en caso de que se presente un conflicto de este tipo, prevalecerá la norma de normas.

b) Motivación: Este uso indica que la expresión es una razón, un motivo o inspiración para efectuar una acción; la expresión es un motivador del orden constitucional basado en un deber ser, lo correcto, es decir que no se trata de indicar que existe normativamente la expresión como mera instrumentalidad, sino que se trata de que se materialice más allá de la ley y pase a ser la idea fundamental de la justicia social.

c) Limitante: En razón a la expresión se limita la potestad de una facultad o poder.

d) Salvedad: Excepción a la norma o regla general, en donde se permite una actividad, conducta, derecho o hecho, que, estando prohibido, por razones en razón a la expresión objeto de estudio se autoriza, como ejemplo en el caso de los monopolios rentísticos.

e) Prohibición: en virtud de la expresión se niegan (vetan) ciertas conductas que de ser permitidas atentan contra un principio. 
El descriptor número dos (2) va encaminado a establecer a quien le compete la expresión utilizada, bien sea al Estado, al ciudadano o ambos:

a) En el caso del estado se puede entender como un deber (obligación, responsabilidad o compromiso), una facultad (potestad, atribución, competencia, poder), o como una finalidad (ideal, objetivo, intención).

b) En el caso del ciudadano se puede entender bien como un deber o como un derecho, como en el caso del pago de impuestos, o en el de elegir y ser elegido.

c) Ambos, la expresión es de la competencia tanto del estado como del ciudadano.

El descriptor número tres (3) trata de señalar la perspectiva que incorpora la expresión o el criterio al que se le da prevalencia, indicando si es netamente económica o incorpora otras esferas que trascienden lo económico, tales como, lo social, lo ambiental, lo cultural u otros; por lo tanto, este descriptor indica si la perspectiva es:
a) Económica
b) No económica
c) Ambas

El descriptor número cuatro (4) señala si para la expresión se han indicado especificidades, con lo que se le da un orden especial bien sea a: a) actividades, b) instituciones o entidades y c) bienes, ya que se definen o demarcan con el carácter de la expresión; esto es relevante dado que se hacen concreciones. Por ejemplo, no es lo mismo decir "las actividades de interés público" que decir "las actividades financiera, bursátil y aseguradora son de interés público".

El descriptor número cinco (5) es inverso al cuatro, dado que señala usos o aplicaciones generales del término sin hacer concreciones, sin definir, o sea que se hace un uso más ambiguo o vago. Una vez desarrollados los descriptores, se buscó cada una de las expresiones en las constituciones de los países señalados, y por cada país se analizó el conjunto de artículos que referían las expresiones para indicar si le aplicaba o no cada uno de los cinco descriptores. Como resultados posibles, a cada expresión podían aplicársele los cinco descriptores o no aplicársele alguno de ellos, y a su vez podía aplicársele varias de las subdivisiones de cada descriptor, dado que se analizó el conjunto de artículos por país. Es de anotar que no todas las expresiones se encuentran en las constituciones de todos los países.

\section{Resultados}

Para esbozar los resultados de este análisis, las veinte expresiones se segregaron en tres grupos:

1. Interés público

2. Expresiones cercanas al interés público 
3. Expresiones complementarias al interés público

En cuanto al primer grupo, es relevante tener en cuenta que se clasificaron específicamente las veces que se encuentra la palabra textual y catalogaron de acuerdo a los descriptores ya definidos previamente. En las expresiones cercanas, aquellas que incorporan la palabra interés y que en ocasiones se usan en el mismo sentido, las cuales son: interés colectivo, interés común, interés de la nación, interés del estado, interés del pueblo, interés general, interés nacional e interés social. En las expresiones complementarias se registraron aquellas que de una u otra manera parecen desarrollar objetivos enmarcados dentro del interés público, tales expresiones son: bien colectivo, bien común, bien general, bienestar colectivo, bienestar común, bienestar de la población, bienestar general, bienestar social, utilidad común, utilidad nacional y utilidad pública. Dado que en expresiones cercanas y complementarias se agruparon varias, en los resultados se expresa el número de países que utilizan los términos en el sentido de cada descriptor.

\section{IV.I. Interés público}

Una vez aplicada la metodología se obtuvo para la expresión Interés Público que:

1. De los trece países analizados, once incorporan la expresión interés público y sólo para nueve de ellos aplica este descriptor (como se ve en la Tabla 1), encontrándose que siete de ellos lo utilizan tanto como una motivación, al igual que como un limitante, mientras que cinco lo utilizan como una salvedad, y ninguno lo utiliza como principio/valor o como prohibición. Adicionalmente, Brasil, México y Panamá le dan los mismos usos: motivación, limitante y salvedad; Chile y Venezuela le dan dos usos: motivación y limitante; Bolivia y Colombia le dan también dos usos: limitante y salvedad; y Ecuador y Perú le dan un solo uso, ambos de motivación.

Tabla 1: Interés público - Descriptor 1

\begin{tabular}{|c|c|c|c|c|c|c|c|c|c|c|c|}
\hline \multicolumn{2}{|c|}{$\begin{array}{c}\text { Paí/ } \\
\text { Descriptor }\end{array}$} & Bolivia & Brasil & Chile & Colombia & Ecuador & México & Panamá & Perú & Venezuela & TOTAL \\
\hline \multirow{5}{*}{ 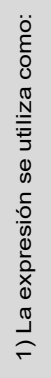 } & $\begin{array}{l}\text { a) Principio } \\
\text { / Valor }\end{array}$ & & & & & & & & & & N/A \\
\hline & $\begin{array}{l}\text { b) } \\
\text { Motivación }\end{array}$ & & $x$ & $x$ & & $x$ & $x$ & $x$ & $x$ & $x$ & 7 \\
\hline & c) Limitante & $x$ & $x$ & $x$ & $x$ & & $x$ & $\mathrm{x}$ & & $x$ & 7 \\
\hline & $\begin{array}{l}\text { d) } \\
\text { Salvedad } \\
\end{array}$ & $x$ & $x$ & & $x$ & & $x$ & $x$ & & & 5 \\
\hline & $\begin{array}{l}\text { e) } \\
\text { Prohibición }\end{array}$ & & & & & & & & & & $N / A$ \\
\hline
\end{tabular}

Fuente: Elaboración propia. 
En los países que se utiliza como una motivación, el interés público es la razón o justificación para actuar en materia de contratación pública, creando empresas estatales, adquiriendo bienes, otorgando o anulando concesiones para la explotación de recursos naturales, para la utilización del agua, de los medios de comunicación o transporte y de otras empresas de servicio público; también es una razón para que el Congreso Nacional convoque a reuniones extraordinarias y de otro lado, es una inspiración o base sobre la que se fundamenta la educación, ya que, esta no debe estar al servicio de intereses individuales o corporativos.

Como hallazgo particular en cuanto a la utilización como una limitación, se encontró que en los países en los cuales se usa, se busca establecer límites a los intereses privados, específicamente a la propiedad privada. Podría decirse que, lo que se pretende es establecer una barrera que sobreponga las generalidades sobre las particularidades, es decir, no se busca beneficiar a un sector o un grupo de personas específico, se procura que toda la población se vea beneficiada.

Ahora bien, cuando se usa como una salvedad se hace en el sentido de que, aunque hay una regla general que determina ciertas conductas o derechos, se puede establecer excepciones amparadas en el interés público, como en los casos de la publicidad de la información, de la tala de árboles protegidos y del monopolio, que, aunque prohibido lo puede ejercer el estado reservándose ciertas actividades, servicios y bienes considerados de carácter estratégico. Por último, los países España y Paraguay no están incluidos en este descriptor, debido a que, se encontró ausencia de uso para la categoría que se definió, pero sí podrá tener uso más adelante en otro de los descriptores.

2. En nueve países se entiende como un deber, facultad o finalidad del Estado que solamente está a cargo de éste, mientras que en dos países se entiende que además del Estado, también le compete al ciudadano, bien sea en el sentido de deber o de derecho y en ninguno de los casos es entendido solamente como un derecho o deber ciudadano, a continuación, se puede observar este hallazgo:

Tabla 2: Interés público - Descriptor 2

\begin{tabular}{|c|c|c|c|c|c|c|c|c|c|c|c|c|c|}
\hline \multicolumn{2}{|c|}{$\begin{array}{c}\text { País/ } \\
\text { Descriptor }\end{array}$} & Bolivia & Brasil & Chile & Colombia & Ecuador & España & México & Panamá & Paraguay & Perú & Venezuela & TOTAL \\
\hline $\begin{array}{l}\ddot{0} \\
\dot{0} \\
0 \\
0 \\
0\end{array}$ & \begin{tabular}{|l|} 
a) Deberl \\
Facultad/ \\
Finalidad \\
del Estado
\end{tabular} & $x$ & $x$ & & $x$ & & $x$ & X & $x$ & $x$ & $x$ & $x$ & 9 \\
\hline 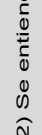 & \begin{tabular}{|l|} 
b) \\
Derechol \\
Deber \\
ciudadano \\
\end{tabular} & & & & & & & & & & & & N/A \\
\hline & c) Ambos & & & $X$ & & $X$ & & & & & & & 2 \\
\hline
\end{tabular}

Fuente: Elaboración propia. 
En los casos en que la expresión se entiende como un deber del Estado, básicamente ese deber está encaminado a la protección y salvaguarda del interés público que puede estar en cabeza del Ministerio Público o del Congreso, adicional ese deber también incorpora el compromiso de promoverlo; en el mismo sentido de protección y promoción se entiende la finalidad del Estado; respecto a la facultad del Estado, esta es en materia de contratación pública y en el sentido de que a éste le compete deliberar sobre cualquier asunto de interés público. Cuando la expresión se entiende como derecho del ciudadano, ese derecho es en función de la participación en asuntos de interés público y cuando se entiende como deber ciudadano, se establece la obligatoriedad sobre el concesionario minero de desarrollar la actividad necesaria para satisfacer el interés público.

3. En seis países incorpora una perspectiva tanto económica, como no económica y cinco países solamente incorporan una de las perspectivas, dos de las cuales son económicas y tres, no económicas, como se muestra en la siguiente tabla:

Tabla 3: Interés público - Descriptor 3

\begin{tabular}{|c|c|c|c|c|c|c|c|c|c|c|c|c|c|}
\hline \multicolumn{2}{|c|}{$\begin{array}{c}\text { País/ } \\
\text { Descriptor }\end{array}$} & Bolivia & Brasil & Chile & Colombia & Ecuador & España & México & Panamá & Paraguay & Perú & Venezuela & TOTAL \\
\hline \multirow{3}{*}{ 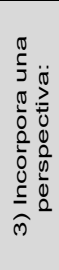 } & \begin{tabular}{|l|} 
a) \\
Económic \\
a
\end{tabular} & & & & $X$ & & X & & & & & & 2 \\
\hline & \begin{tabular}{|lr} 
b) & No \\
económica
\end{tabular} \mid & & & & & $x$ & & & $x$ & $x$ & & & 3 \\
\hline & c) Ambas & $x$ & $x$ & $x$ & & & & $x$ & & & $x$ & $x$ & 6 \\
\hline
\end{tabular}

Fuente: Elaboración propia.

En el caso en que la expresión incorpora una perspectiva económica, esta se enfoca en la propiedad privada, la intervención económica, los intereses patrimoniales de la República y las actividades económicas. Mientras que en los países que incorpora una perspectiva no económica, se desarrollan temas de recursos naturales, patrimonio natural histórico, patrimonio cultural, desarrollo rural, reconocimiento de la organización social de comunidades indígenas, empresas del sector social y derecho a la educación, a la participación, a presentar tutelas, al acceso a la información y al conocimiento. Lo anterior podría estar muy relacionado con el papel que juega el Estado como garante de los derechos humanos a todos los habitantes del territorio, es decir, quien tiene la obligación de velar por la calidad y el bienestar de la población es precisamente el Estado, por ende, cada acción que se ejecutada para dicho fin, 
se cataloga dentro de las Constituciones, objeto de estudio, como de interés público.

4. En seis países explícitamente se menciona que hay actividades catalogadas como de interés público, en uno se reconocen instituciones o entidades de interés público, en dos países se declara el interés público sobre bienes y en cinco países no se otorga un orden especial a ninguna de las categorías, por lo tanto, no les aplica este descriptor como se observa en la tabla 4:

Tabla 4: Interés público - Descriptor 4

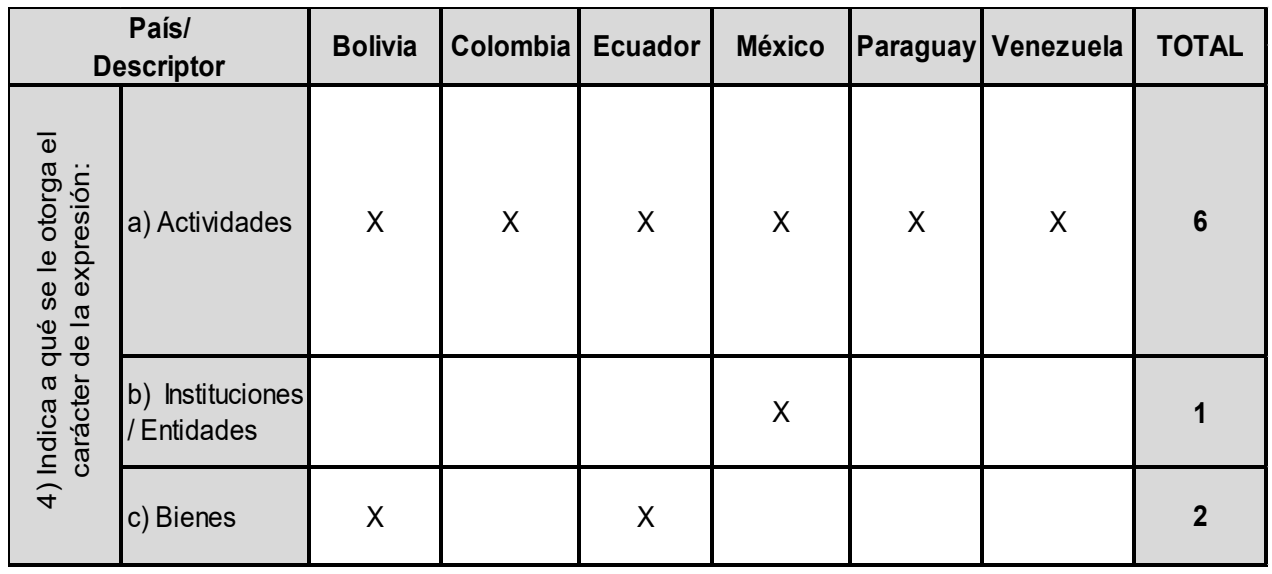

Fuente: Elaboración propia.

Cuando se otorga el carácter de interés público sobre actividades económicas, se hace sobre las actividades financiera, bursátil, aseguradora, agropecuaria, la ciencia, la tecnología, aquellas relacionadas con la prevención, conservación y recuperación del medio ambiente, los servicios de organización y funcionamiento del Registro Nacional de Ciudadanos, los servicios de información y el empleo de los medios de comunicación. En cuanto a las organizaciones que desempeñan actividades financieras, podría decirse que, adquieren este calificativo de interés público debido a que, al captar los recursos del público para obtener una rentabilidad a través de la financiación de quien lo requiere, se ejerce una tarea de alta responsabilidad cuya vigilancia por parte del Estado debe ser muy rigurosa.

En México que es el único país que otorga el carácter de interés público sobre instituciones o entidades, efectúa dicho reconocimiento a las comunidades indígenas y a los partidos políticos. Por otro lado, en los países que se otorga el carácter de interés público sobre los bienes, se hace sobre la 
biodiversidad, la integridad del patrimonio genético, el patrimonio natural y los recursos naturales. Adicional a lo anterior, se resalta el hecho de que, en países como: Argentina, Brasil, Chile, Panamá, Perú, Uruguay y España, no se indica a que se le otorga el carácter de la expresión, es decir, el uso del término puede clasificarse dentro de otro descriptor.

5. Finalmente, nueve de los países incorporan la expresión sin definirla, es decir, hacen un uso o aplicación, pero no se encuentra un contexto que permita al lector identificar la particularidad a la que se hace referencia. Podría decirse que, en algunas de las Constituciones se utiliza como un calificativo o sustantivo de determinada cosa o acción, a continuación, se presentan los resultados:

Tabla 5: Interés público - Descriptor 5

\begin{tabular}{|c|c|c|c|c|c|c|c|c|c|c|c|}
\hline \multicolumn{2}{|c|}{$\begin{array}{c}\text { País/ } \\
\text { Descriptor }\end{array}$} & Bolivia & Chile & Colombia & Ecuador & España & Panamá & Paraguay & Perú & Venezuela & TOTAL \\
\hline 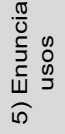 & usos & $x$ & $x$ & $x$ & $x$ & $x$ & $x$ & $x$ & $x$ & $x$ & 9 \\
\hline
\end{tabular}

Fuente: Elaboración propia.

En los casos en que se enuncian usos de la aplicación, es porque se hace de manera más genérica y no se le imputa como tal ese carácter especial de interés público, los usos encontrados son: asuntos de interés público, obras de interés público, contratos de interés público, contratos de interés público referidos a recursos naturales y áreas estratégicas, actividades de interés público y actividad petrolera y otras industrias, explotaciones, servicios y bienes de interés público.

\section{IV.II. Expresiones cercanas}

Las expresiones que se usan como expresiones cercanas al interés público, son aquellas que en ocasiones se emplean en el mismo sentido e incorporan la palabra "interés", tales como interés colectivo, interés común, interés de la nación, interés del estado, interés del pueblo, interés general, interés nacional e interés social; las cuales se analizaron globalmente encontrándose que:

1. Las expresiones son utilizadas en gran medida como una motivación, dado que, de los trece países, se encuentran 33 aplicaciones en este sentido; a su vez, otro de los usos se da en el sentido de limitante con 19 aplicaciones, como se observa en la Tabla 7: 
Pulgarín, Bustamante, Zapata. Noción de interés público en las constituciones de Iberoamérica

Tabla 6: Expresiones cercanas - Descriptor 1

\begin{tabular}{|c|c|c|c|c|c|c|c|c|c|c|}
\hline \multicolumn{2}{|c|}{$\begin{array}{l}\text { Descriptor/ } \\
\text { Concepto }\end{array}$} & \multirow[t]{2}{*}{\begin{tabular}{|c|} 
Interés \\
Colectivo
\end{tabular}} & \multirow[t]{2}{*}{$\begin{array}{l}\text { Interés } \\
\text { común }\end{array}$} & \multirow[t]{2}{*}{$\begin{array}{c}\text { Interés de la } \\
\text { nación }\end{array}$} & \multirow[t]{2}{*}{$\begin{array}{c}\text { Interés } \\
\text { del } \\
\text { Estado }\end{array}$} & \multirow[t]{2}{*}{$\begin{array}{c}\text { Interés } \\
\text { del } \\
\text { pueblo }\end{array}$} & \multirow{2}{*}{$\begin{array}{c}\text { Interés } \\
\text { general }\end{array}$} & \multirow{2}{*}{$\begin{array}{c}\begin{array}{c}\text { Interés } \\
\text { nacional }\end{array} \\
\end{array}$} & \multirow{2}{*}{$\begin{array}{c}\begin{array}{c}\text { Interés } \\
\text { social }\end{array} \\
1\end{array}$} & \multirow{2}{*}{$\begin{array}{c}\begin{array}{c}\text { Total } \\
\text { sinónimos }\end{array} \\
3\end{array}$} \\
\hline \multirow{5}{*}{ 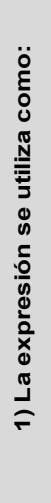 } & $\begin{array}{l}\text { a) Principio } \\
\text { / Valor }\end{array}$ & & & & & & & & & \\
\hline & $\begin{array}{l}\text { b) } \\
\text { Motivación }\end{array}$ & 4 & 2 & 1 & 3 & 3 & 6 & 6 & 8 & 33 \\
\hline & c) Limitante & 1 & 1 & 1 & & & 7 & 2 & 7 & 19 \\
\hline & $\begin{array}{l}\text { d) } \\
\text { Salvedad }\end{array}$ & 1 & & & 1 & & 2 & 3 & 2 & 9 \\
\hline & $\begin{array}{l}\text { e) } \\
\text { Prohibición }\end{array}$ & 1 & & & & & & 4 & 1 & 6 \\
\hline
\end{tabular}

Fuente: Elaboración propia.

Las materias en las que se utilizan las expresiones en el sentido de representar una motivación o justificación son: regulación de actividades económicas, en especial el sistema financiero, regulación de relaciones internacionales y de recursos genéticos; delegación de participación en sectores estratégicos; concesión de la prestación de servicios públicos, o explotación, uso y aprovechamiento tanto de bienes de dominio del Estado, como de recursos naturales; estimulación de áreas estratégicas como la ciencia, la investigación científica, tecnológica y técnica o de actividades como las agropecuarias y el turismo; expropiación de bienes y reserva de determinadas actividades estratégicas o servicios públicos; y actuación del Estado en defensa y promoción de los intereses que abarca esta clasificación.

Cuando se utiliza en el sentido de limitante, se enfoca en restringir la potestad principalmente sobre la propiedad privada y en menor uso sobre otros derechos como la vida, el honor, la libertad, la seguridad, el trabajo y la huelga; otros temas que también se limitan son: el interés particular, la actividad económica y recursos o servicios esenciales que se reservan al sector público.

2. Las expresiones cercanas se entienden esencialmente como un deber, facultad o finalidad que compete exclusivamente al Estado, encontrándose al respecto 32 aplicaciones, seguido de 16 aplicaciones que las vinculan tanto al Estado como al ciudadano y en 7 aplicaciones las asocian exclusivamente al ciudadano, ya sea como un derecho o un deber. 
Tabla 7: Expresiones cercanas - Descriptor 2

\begin{tabular}{|c|c|c|c|c|c|c|c|c|c|c|}
\hline \multicolumn{2}{|c|}{$\begin{array}{l}\text { Descriptorl } \\
\text { Concepto }\end{array}$} & $\begin{array}{l}\text { Interés } \\
\text { Colectivo }\end{array}$ & $\begin{array}{l}\text { Interés } \\
\text { común }\end{array}$ & $\begin{array}{c}\text { Interés de la } \\
\text { nación }\end{array}$ & $\begin{array}{l}\text { Interés } \\
\text { del } \\
\text { Estado }\end{array}$ & $\begin{array}{c}\text { Interés } \\
\text { del } \\
\text { pueblo }\end{array}$ & $\begin{array}{l}\text { Interés } \\
\text { general }\end{array}$ & \begin{tabular}{|c|} 
Interés \\
nacional
\end{tabular} & $\begin{array}{l}\text { Interés } \\
\text { social }\end{array}$ & $\begin{array}{c}\text { Total } \\
\text { sinónimos }\end{array}$ \\
\hline \multirow{3}{*}{ 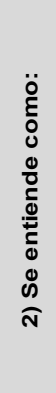 } & $\begin{array}{l}\text { a) Deber/ } \\
\text { Facultad/ } \\
\text { Finalidad } \\
\text { del Estado }\end{array}$ & 1 & 3 & 2 & 6 & 2 & 4 & 8 & 6 & 32 \\
\hline & $\begin{array}{l}\text { b) Derecho/ } \\
\text { Deber } \\
\text { ciudadano }\end{array}$ & 1 & 1 & 1 & & & 3 & & 1 & 7 \\
\hline & c) Ambos & 4 & & & & 1 & 5 & 3 & 3 & 16 \\
\hline
\end{tabular}

Fuente: Elaboración propia.

Para los casos en los que se entiende las expresiones como competencia del Estado, por un lado, incorporan un deber de promoción y salvaguarda al que en ocasiones le asignan el responsable de su protección, dentro de los que se encuentran: la Contraloría General, el Ministerio Público, el Ministerio fiscal, la Procuraduría General y las Superintendencias; de otro lado, refieren tanto una facultad, como una finalidad del Estado para actuar en pro de los intereses de esta categoría.

En los casos que dichas expresiones se entienden asociadas al ciudadano aluden en mayor proporción derechos de primera, segunda y tercera generación y en menor medida el deber de protección y el de anteponer los intereses de esta categoría al interés particular.

3. Las expresiones cercanas incorporan una perspectiva que en términos generales no es exclusivamente económica o no económica, sino que tienen una combinación como se muestra a continuación con 32 aplicaciones. Ver Tabla 9.

Tabla 8: Expresiones cercanas - Descriptor 3

\begin{tabular}{|c|c|c|c|c|c|c|c|c|c|c|}
\hline \multicolumn{2}{|c|}{$\begin{array}{l}\text { Descriptor/ } \\
\text { Concepto }\end{array}$} & $\begin{array}{c}\text { Interés } \\
\text { Colectivo }\end{array}$ & $\begin{array}{l}\text { Interés } \\
\text { común }\end{array}$ & $\begin{array}{c}\text { Interés de la } \\
\text { nación }\end{array}$ & $\begin{array}{l}\text { Interés } \\
\text { del } \\
\text { Estado }\end{array}$ & $\begin{array}{c}\text { Interés } \\
\text { del } \\
\text { pueblo }\end{array}$ & $\begin{array}{l}\text { Interés } \\
\text { general }\end{array}$ & $\begin{array}{c}\text { Interés } \\
\text { nacional }\end{array}$ & $\begin{array}{r}\text { Interés } \\
\text { social }\end{array}$ & $\begin{array}{c}\text { Total } \\
\text { sinónimos }\end{array}$ \\
\hline \multirow{3}{*}{ 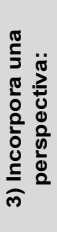 } & $\begin{array}{l}\text { a) } \\
\text { Económica }\end{array}$ & & & 1 & 4 & & & 5 & & 10 \\
\hline & $\begin{array}{l}\text { b) No } \\
\text { económica }\end{array}$ & 2 & 2 & 2 & 1 & & 4 & 1 & 1 & 13 \\
\hline & c) Ambas & 4 & 2 & & 1 & 3 & 8 & 5 & 9 & 32 \\
\hline
\end{tabular}

Fuente: Elaboración propia. 
Se puede inferir entonces que, los diferentes sinónimos cuyas aplicaciones fueron encontradas dentro de las Constituciones analizadas, no se emplean en una perspectiva específica ya sea económica o no económica. Mas bien, puede decirse que estos términos, catalogados como cercanos, no cuentan con una definición específica que pueda delimitar su incorporación en la normatividad relacionada con alguna de estas perspectivas.

4. El carácter de las expresiones cercanas se otorga principalmente a bienes y en segundo lugar a actividades y aplica sólo para cuatro de las ocho expresiones clasificadas como sinónimos:

Tabla 9: Expresiones cercanas - Descriptor 4

\begin{tabular}{|c|c|c|c|c|c|c|c|c|c|c|}
\hline \multicolumn{2}{|c|}{$\begin{array}{l}\text { Descriptor/ } \\
\text { Concepto }\end{array}$} & $\begin{array}{c}\text { Interés } \\
\text { Colectivo }\end{array}$ & $\begin{array}{l}\text { Interés } \\
\text { común }\end{array}$ & $\begin{array}{c}\text { Interés de la } \\
\text { nación }\end{array}$ & $\begin{array}{c}\text { Interés } \\
\text { del } \\
\text { Estado }\end{array}$ & $\begin{array}{c}\text { Interés } \\
\text { del } \\
\text { pueblo }\end{array}$ & $\begin{array}{l}\text { Interés } \\
\text { general }\end{array}$ & $\begin{array}{c}\text { Interés } \\
\text { nacional }\end{array}$ & $\begin{array}{l}\text { Interés } \\
\text { social }\end{array}$ & $\begin{array}{c}\text { Total } \\
\text { sinónimos }\end{array}$ \\
\hline \multirow{3}{*}{ 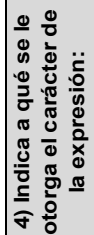 } & $\begin{array}{l}\text { a) } \\
\text { Actividades }\end{array}$ & 1 & & & & & 2 & 1 & 1 & 5 \\
\hline & \begin{tabular}{|l|} 
b) \\
Instituciones \\
/ Entidades \\
\end{tabular} & 1 & & & & & & & & 1 \\
\hline & c) Bienes & 2 & & & & & 1 & 2 & 2 & 7 \\
\hline
\end{tabular}

Fuente: Elaboración propia.

Cuando se le otorga el carácter de la expresión a actividades se encuentra que la producción de alimentos (actividades: agrícola, pecuaria, pesquera y acuícola) y el turismo son de interés nacional; las telecomunicaciones y la radiodifusión son servicios públicos de interés general; la protección del medio ambiente, la gestión sustentable, solidaria con las generaciones futuras, de los recursos hídricos y la preservación del ciclo hidrológico son de interés general; la preservación, la conservación, la recomposición y el mejoramiento del ambiente, así como su conciliación con el desarrollo humano integral son de interés social; la libre competencia económica es de interés colectivo. Cuando se le otorga el carácter de la expresión a entidades se concibe que las cooperativas de servicios públicos son organizaciones de interés colectivo.

Cuando se le otorga el carácter de la expresión a bienes se presenta que el patrimonio, el espacio, la seguridad, la salubridad pública y el medio ambiente son de interés colectivo; el dominio público hidráulico (aguas superficiales y subterráneas, con excepción de las pluviales) es de interés general; los vestigios o restos fósiles, los monumentos arqueológicos, artísticos e históricos y las zonas turísticas son declaradas de interés nacional; el bien inmueble y el bien de familia son declarados como de interés social.

5. El carácter de las expresiones cercanas enuncia usos para las expresiones: interés colectivo, interés común, interés general, interés nacional e interés social: 
Tabla 10: Expresiones cercanas - Descriptor 5

\begin{tabular}{|c|c|c|c|c|c|c|c|c|c|c|}
\hline \multicolumn{2}{|c|}{$\begin{array}{l}\text { Descriptor/ } \\
\text { Concepto }\end{array}$} & \begin{tabular}{|c|} 
Interés \\
Colectivo
\end{tabular} & $\begin{array}{l}\text { Interés } \\
\text { común }\end{array}$ & $\begin{array}{c}\text { Interés de la } \\
\text { nación }\end{array}$ & $\begin{array}{c}\text { Interés } \\
\text { del } \\
\text { Estado }\end{array}$ & $\begin{array}{c}\text { Interés } \\
\text { del } \\
\text { pueblo }\end{array}$ & $\begin{array}{l}\text { Interés } \\
\text { general }\end{array}$ & $\begin{array}{c}\text { Interés } \\
\text { nacional }\end{array}$ & $\begin{array}{l}\text { Interés } \\
\text { social }\end{array}$ & $\begin{array}{c}\text { Total } \\
\text { sinónimos }\end{array}$ \\
\hline 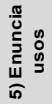 & usos & 2 & 2 & & & & 4 & 2 & 1 & 11 \\
\hline
\end{tabular}

Fuente: Elaboración propia.

En los casos en que enuncia usos, simplemente se incorpora la expresión como forma de aplicación, diferente de lo que sucede con el descriptor número cuatro que define. Los usos encontrados son: información de interés colectivo, funciones públicas de interés común, normas generales de interés común, procesos de interés general, asuntos de interés general, materia de información estadística y geográfica de interés nacional, obras públicas de interés nacional, contratos de interés nacional, políticas de interés nacional, y contenido de interés social.

\section{IV.III. Expresiones complementarias}

Los términos que se usan como expresiones complementarias, se dirigen a objetivos afines o complementarios del interés público, tales como bien colectivo, bien común, bien general, bienestar colectivo, bienestar común, bienestar de la población, bienestar general, bienestar social, utilidad común, utilidad nacional, utilidad pública. Estas se analizaron globalmente encontrándose que:

1. Las expresiones complementarias se utilizan en mayor proporción como motivación encontrándose 28 aplicaciones de las expresiones que componen este grupo; seguidamente se encuentra en igual proporción el uso como principio/valor y limitante con 10 aplicaciones.

Tabla 11: Expresiones complementarias - Descriptor 1

\begin{tabular}{|c|c|c|c|c|c|c|c|c|c|c|c|c|c|}
\hline \multicolumn{2}{|c|}{$\begin{array}{l}\text { Descriptorl } \\
\text { Concepto }\end{array}$} & \multirow{2}{*}{\begin{tabular}{|c}
$\begin{array}{c}\text { Bien } \\
\text { colectivo }\end{array}$ \\
1
\end{tabular}} & \multirow{2}{*}{\begin{tabular}{|c}
$\begin{array}{c}\text { Bien } \\
\text { común }\end{array}$ \\
4 \\
\end{tabular}} & \multirow{2}{*}{$\begin{array}{c}\begin{array}{c}\text { Bien } \\
\text { general }\end{array} \\
1\end{array}$} & \multirow{2}{*}{\begin{tabular}{|l}
$\begin{array}{l}\text { Bienestar } \\
\text { colectivo }\end{array}$ \\
\end{tabular}} & \multirow{2}{*}{$\begin{array}{c}\begin{array}{c}\text { Bienestar } \\
\text { común }\end{array} \\
1\end{array}$} & \multirow{2}{*}{\begin{tabular}{|c|}
$\begin{array}{c}\text { Bienestar } \\
\text { de la } \\
\text { población }\end{array}$ \\
\\
\end{tabular}} & \multirow{2}{*}{\begin{tabular}{|c|}
$\begin{array}{c}\text { Bienestar } \\
\text { general }\end{array}$ \\
\\
3
\end{tabular}} & \multirow[t]{2}{*}{$\begin{array}{c}\text { Bienestar } \\
\text { social }\end{array}$} & \multirow[t]{2}{*}{$\begin{array}{l}\text { Utilidad } \\
\text { común }\end{array}$} & \multirow[t]{2}{*}{$\begin{array}{c}\text { Utilidad } \\
\text { nacional }\end{array}$} & \multirow[t]{2}{*}{$\begin{array}{l}\text { Utilidad } \\
\text { pública }\end{array}$} & \multirow{2}{*}{\begin{tabular}{|c}
$\begin{array}{r}\text { Total } \\
\text { similare }\end{array}$ \\
10
\end{tabular}} \\
\hline$\ddot{0}$ & $\begin{array}{l}\text { a) Principio } \\
\text { /Valor }\end{array}$ & & & & & & & & & & & & \\
\hline$\stackrel{\frac{\pi}{5}}{\frac{\underline{E}}{3}}$ & $\begin{array}{l}\text { b) } \\
\text { Motivación }\end{array}$ & & & 1 & 2 & 1 & 4 & 3 & 3 & 1 & 1 & 12 & 28 \\
\hline$\frac{5}{0}$ & c) Limitante & 1 & 3 & & 1 & & 1 & & & & & 4 & 10 \\
\hline 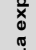 & d) Salvedac & & & & & & & & & & & 1 & 1 \\
\hline & $\begin{array}{l}\text { e) } \\
\text { Prohibición }\end{array}$ & & & & & & & & & & & 1 & 1 \\
\hline
\end{tabular}

Fuente: Elaboración propia. 
Las materias en las que se utilizan las expresiones en el sentido de representar una motivación son: promoción del desarrollo económico, de la estabilidad económica, de la actividad económica, en especial la manufactura nacional de materias primas, del mercado interno, de la seguridad social, de la educación, de la participación comunitaria y de políticas de descentralización; administración y gestión de recursos naturales; concesión para la explotación de recursos naturales, de medios de comunicación o transporte y de otras empresas de servicio público; suscripción de tratados internacionales; imposición de contribuciones directas; creación de organizaciones, cooperativas y empresas comunales de servicios; fusión o asociación de Municipios; establecimiento de legislación exclusiva; expropiación de la propiedad privada; cumplimiento de la función social del estado.

Cuando se utiliza en el sentido de principio lo refiere como principio del Estado, de la organización territorial, de la economía plural, de la actuación del presidente, el vicepresidente, los miembros de cuerpos colegiados y como principio sobre el que se fundamenta la justicia y el desarrollo integral y equilibrado de la Nación; cuando se utiliza como valor se da en el sentido de considerar como valor del Estado las expresiones: bien común, bienestar común y bienestar general. Cuando se utiliza en como limitante se restringe la actividad económica, la propiedad privada, el interés privado, el uso de los recursos hídricos y recursos naturales y el derecho de huelga.

2. Las expresiones complementarias se entienden principalmente como competencia exclusiva del Estado con 34 aplicaciones, seguidas de 8 aplicaciones que lo entienden como una combinación que compete tanto al Estado como al ciudadano y 3 aplicaciones como exclusivas del ciudadano.

Tabla 12: Expresiones complementarias - Descriptor 2

\begin{tabular}{|c|c|c|c|c|c|c|c|c|c|c|c|c|c|}
\hline \multicolumn{2}{|c|}{$\begin{array}{l}\text { Descriptorl } \\
\text { Concepto }\end{array}$} & \multirow{2}{*}{\begin{tabular}{|c|}
$\begin{array}{c}\text { Bien } \\
\text { colectivo }\end{array}$ \\
\end{tabular}} & \multirow{2}{*}{$\begin{array}{c}\begin{array}{c}\text { Bien } \\
\text { común }\end{array} \\
4\end{array}$} & \multirow{2}{*}{$\begin{array}{c}\begin{array}{c}\text { Bien } \\
\text { general }\end{array} \\
2\end{array}$} & \multirow{2}{*}{ 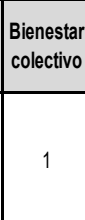 } & \multirow{2}{*}{$\begin{array}{c}\begin{array}{c}\text { Bienestar } \\
\text { común }\end{array} \\
2\end{array}$} & \multirow{2}{*}{$\begin{array}{c}\begin{array}{c}\text { Bienestar } \\
\text { de la } \\
\text { población }\end{array} \\
5\end{array}$} & \multirow{2}{*}{ 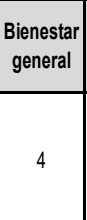 } & \multirow{2}{*}{\begin{tabular}{|c}
$\begin{array}{c}\text { Bienestar } \\
\text { social }\end{array}$ \\
2 \\
\end{tabular}} & \multirow{2}{*}{$\begin{array}{c}\begin{array}{c}\text { Utilidad } \\
\text { común }\end{array} \\
2\end{array}$} & \multirow{2}{*}{$\begin{array}{c}\begin{array}{c}\text { Utilidad } \\
\text { nacional }\end{array} \\
\\
1\end{array}$} & \multirow{2}{*}{$\begin{array}{c}\begin{array}{c}\text { Utilidad } \\
\text { pública }\end{array} \\
11\end{array}$} & \multirow{2}{*}{$\begin{array}{c}\begin{array}{c}\text { Total } \\
\text { similares }\end{array} \\
34\end{array}$} \\
\hline $\begin{array}{l}\ddot{0} \\
\ddot{g} \\
0 \\
0\end{array}$ & $\begin{array}{l}\text { a) Deber/ } \\
\text { Facultad/ } \\
\text { Finalidad } \\
\text { del Estado }\end{array}$ & & & & & & & & & & & & \\
\hline 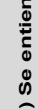 & $\begin{array}{l}\text { b) Derechol } \\
\text { Deber } \\
\text { ciudadano }\end{array}$ & & 2 & & & & & 1 & & & & & 3 \\
\hline & c) Ambos & 1 & & & 3 & & & 1 & 2 & & & 1 & 8 \\
\hline
\end{tabular}

Fuente: Elaboración propia.

Cuando se entiende como deber del Estado, está dado en función de garantizar, proteger, promover y proveer lo que implica las expresiones de esta categoría, las cuales en algunos casos están a cargo del Presidente, 
vicepresidente o el Congreso; la finalidad del estado es similar en el sentido de promover y garantizar lo que promulgan las expresiones; y la facultad del Estado se entiende para imponer contribuciones, legislación exclusiva, efectuar expropiación, asociarse con Municipios y celebrar tratados. En los casos que se entiende como derechos del ciudadano, se relacionan la salud, la educación, el trabajo, la seguridad social, los servicios públicos, la propiedad privada y la actividad económica lícita; finalmente, el deber del ciudadano respecto a las expresiones similares es promoverlas.

3. Respecto a la perspectiva de las expresiones complementarias, en términos generales se puede decir que su perspectiva es económica con 18 aplicaciones, pero como se observa en la Tabla 14, la utilidad pública puede distorsionar esta afirmación, dado que esta se utiliza en los 13 países, con 12 aplicaciones en sentido económico y uno no económico, mientras que el resto de expresiones no son usadas por la totalidad de los países, de modo que si se suprimiera dicha expresión, el resultado es que las expresiones similares incorporan exclusivamente una perspectiva no económica o una mezcla de las dos perspectivas en igual proporción.

Tabla 13: Expresiones complementarias - Descriptor 3

\begin{tabular}{|c|c|c|c|c|c|c|c|c|c|c|c|c|c|}
\hline \multicolumn{2}{|c|}{$\begin{array}{l}\text { Descriptorl } \\
\text { Concepto }\end{array}$} & $\begin{array}{c}\text { Bien } \\
\text { colectivo }\end{array}$ & $\begin{array}{l}\text { Bien } \\
\text { común }\end{array}$ & $\begin{array}{l}\text { Bien } \\
\text { general }\end{array}$ & $\begin{array}{l}\text { Bienestar } \\
\text { colectivo }\end{array}$ & $\begin{array}{c}\text { Bienestar } \\
\text { común }\end{array}$ & \begin{tabular}{|c} 
Bienestar \\
de la \\
población
\end{tabular} & $\begin{array}{c}\text { Bienestar } \\
\text { general }\end{array}$ & $\begin{array}{c}\text { Bienestar } \\
\text { social }\end{array}$ & $\begin{array}{l}\text { Utilidad } \\
\text { común }\end{array}$ & \begin{tabular}{|l|} 
Utilidad \\
nacional
\end{tabular} & $\begin{array}{l}\text { Utilidad } \\
\text { pública }\end{array}$ & \begin{tabular}{|c} 
Total \\
similares
\end{tabular} \\
\hline \multirow{3}{*}{ 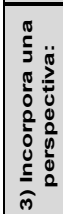 } & $\begin{array}{l}\text { a) } \\
\text { Económica }\end{array}$ & & 1 & 1 & & & 2 & 1 & & & 1 & 12 & 18 \\
\hline & $\begin{array}{|lr|}\text { b) } & \text { No } \\
\text { económica } \\
\end{array}$ & & 3 & 1 & 1 & 2 & & 4 & 2 & & & 1 & 14 \\
\hline & c) Ambas & 1 & 2 & & 3 & & 3 & 1 & 2 & 2 & & & 14 \\
\hline
\end{tabular}

Fuente: Elaboración propia.

De los términos complementarios más utilizados en la perspectiva no económica se encuentran: bien común y bienestar general, lo cual puede estar relacionado con la prevalencia de las acciones del Estado encaminadas a favorecer la calidad de vida, es decir, garantizar un bienestar a la población. Mientras que, en los usos clasificados en ambas perspectivas, los conceptos más utilizados son: bienestar colectivo y bienestar de la población. En estos términos más utilizados se puede hallar una relación y es, precisamente, el hecho de contener palabras como colectivo, común, general, e incluso población, lo cual puede apuntar a una necesidad de promover programas, proyectos y acciones, cuyos beneficiarios sean la mayor cantidad de personas posible. 
4. En las expresiones complementarias, sólo se otorga el carácter de utilidad pública a actividades con dos aplicaciones y de bien común sobre bienes con una aplicación.

Tabla 15: Expresiones complementarias - Descriptor 4

\begin{tabular}{|c|c|c|c|c|c|c|c|c|c|c|c|c|c|}
\hline \multicolumn{2}{|c|}{$\begin{array}{l}\text { Descriptorl } \\
\text { Concepto }\end{array}$} & \multirow[t]{2}{*}{$\begin{array}{c}\text { Bien } \\
\text { colectivo }\end{array}$} & \multirow[t]{2}{*}{$\begin{array}{l}\text { Bien } \\
\text { común }\end{array}$} & \multirow[t]{2}{*}{$\begin{array}{l}\text { Bien } \\
\text { general }\end{array}$} & \multirow[t]{2}{*}{$\begin{array}{l}\text { Bienestar } \\
\text { colectivo }\end{array}$} & \multirow[t]{2}{*}{$\begin{array}{c}\text { Bienestar } \\
\text { común }\end{array}$} & \multirow[t]{2}{*}{$\begin{array}{c}\text { Bienestar } \\
\text { de la } \\
\text { población }\end{array}$} & \multirow[t]{2}{*}{$\begin{array}{c}\text { Bienestar } \\
\text { general }\end{array}$} & \multirow[t]{2}{*}{$\begin{array}{c}\text { Bienestar } \\
\text { social }\end{array}$} & \multirow[t]{2}{*}{$\begin{array}{l}\text { Utilidad } \\
\text { común }\end{array}$} & \multirow[t]{2}{*}{$\begin{array}{c}\text { Utilidad } \\
\text { nacional }\end{array}$} & \multirow{2}{*}{$\begin{array}{c}\begin{array}{c}\text { Utilidad } \\
\text { pública }\end{array} \\
2\end{array}$} & \multirow{2}{*}{$\begin{array}{c}\begin{array}{c}\text { Total } \\
\text { similares }\end{array} \\
2\end{array}$} \\
\hline $\begin{array}{lll}0 & 0 \\
0 & 0 \\
0 & 0 & 0 \\
0 & 0 & 0 \\
0 & 0 & 0\end{array}$ & a) Actividades & & & & & & & & & & & & \\
\hline 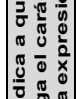 & $\begin{array}{l}\text { b) } \\
\text { Instituciones } \\
\text { Entidades }\end{array}$ & & & & & & & & & & & & 0 \\
\hline$\frac{0}{8}$ & c) Bienes & & 1 & & & & & & & & & & 1 \\
\hline
\end{tabular}

Fuente: Elaboración propia.

En este sentido se halla que las actividades de exploración, explotación, refinación, industrialización, transporte y comercialización de los recursos naturales no renovables tienen el carácter de utilidad pública; además, son de utilidad pública aquellas relacionadas a la seguridad social. Respecto a los bienes, las áreas protegidas constituyen un bien común y forman parte del patrimonio natural y cultural del país.

5. Las expresiones complementarias presentan 6 aplicaciones en cuatro de ellas.

Tabla 16: Expresiones complementarias - Descriptor 5

\begin{tabular}{|c|c|c|c|c|c|c|c|c|c|c|c|c|c|}
\hline \multicolumn{2}{|c|}{$\begin{array}{l}\text { Descriptorl } \\
\text { Concepto }\end{array}$} & $\begin{array}{c}\text { Bien } \\
\text { colectivo }\end{array}$ & $\begin{array}{l}\text { Bien } \\
\text { común }\end{array}$ & $\begin{array}{c}\text { Bien } \\
\text { general }\end{array}$ & $\begin{array}{l}\text { Bienestar } \\
\text { colectivo }\end{array}$ & $\begin{array}{c}\text { Bienestar } \\
\text { común }\end{array}$ & $\begin{array}{c}\text { Bienestar } \\
\text { de la } \\
\text { población }\end{array}$ & $\begin{array}{c}\text { Bienestar } \\
\text { general }\end{array}$ & $\begin{array}{c}\text { Bienestar } \\
\text { social }\end{array}$ & $\begin{array}{l}\text { Utilidad } \\
\text { común }\end{array}$ & $\begin{array}{l}\text { Utilidad } \\
\text { nacional }\end{array}$ & $\begin{array}{l}\text { Utilidad } \\
\text { pública }\end{array}$ & $\begin{array}{c}\text { Total } \\
\text { similares }\end{array}$ \\
\hline 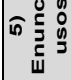 & usos & & & & & & & & 1 & 2 & 1 & 2 & 6 \\
\hline
\end{tabular}

Fuente: Elaboración propia.

Los usos o aplicaciones de las expresiones son: programas de bienestar social, trabajos de utilidad común, asociaciones de utilidad común no gubernamentales, instituciones de utilidad común, empresas de utilidad nacional, establecimientos de utilidad nacional, servicios de utilidad pública y empresas de utilidad pública.

En las constituciones de los países Iberoamericanos analizados, las expresiones tanto de interés público, como de las cercanas y complementarias, acorde con la Gráfica 1, se utilizan en un $48,92 \%$ como una motivación; lo cual 
es un asunto de fuertes críticas, dado que el uso de la expresión, por sí misma permite generar una justificación válida sin más cuestionamientos, tal como lo plantea Rodríguez (1994) al referir que la Corte Constitucional ha resuelto asuntos que implicaban de un análisis profundo con la simple invocación del concepto.

Otro de los mayores usos, se presenta en el sentido de utilizar las expresiones como limitante (Comentario del profe: Sentencia T-517-06

Los artículos 150 numeral 19, 189 numeral 24 y 335 de la Constitución Política prescriben que las actividades financiera, bursátil, aseguradora y cualquier otra relacionada con el manejo, aprovechamiento e inversión de los recursos captados del público se consideran de interés público y que estarán sujetas a la intervención, vigilancia y control estatal y sólo pueden ser ejercidas previa autorización del Estado.

Esto significa que la libertad contractual en materia de seguros, por ser de interés público se restringe cuando están de por medio valores y principios constitucionales, así como la protección de derechos fundamentales, o consideraciones de interés general) de la potestad de los derechos con un 25,9\%; esta limitación se justifica de acuerdo con Rodríguez (1994) apoyada en el ideal de favorecer un grupo mayoritario o en el cumplimiento de metas sociales como lo son la paz o la seguridad. Así mismo, Huerta (2007) dice que "El interés público es la justificación de habilitaciones constitucionales interventoras expresas, así como límite y garantía de derechos individuales y colectivos". (p. 155)

En la misma dirección se encuentra que la Corte Constitucional en Sentencia C-306-13, argumenta la limitación de derechos y en tal sentido afirma que

La concepción actual del Estado, según el preámbulo y los artículos $1^{\circ}$ y $2^{\circ}$ de la carta política, aun cuando consagra la garantía de determinados derechos del hombre y de los asociados, también conduce, dentro de una axiología fijada por el constituyente, a justificar determinadas limitaciones por su intervención bajo la noción del interés público.

Gráfica 1: Usos del total de expresiones (Descriptor 1)

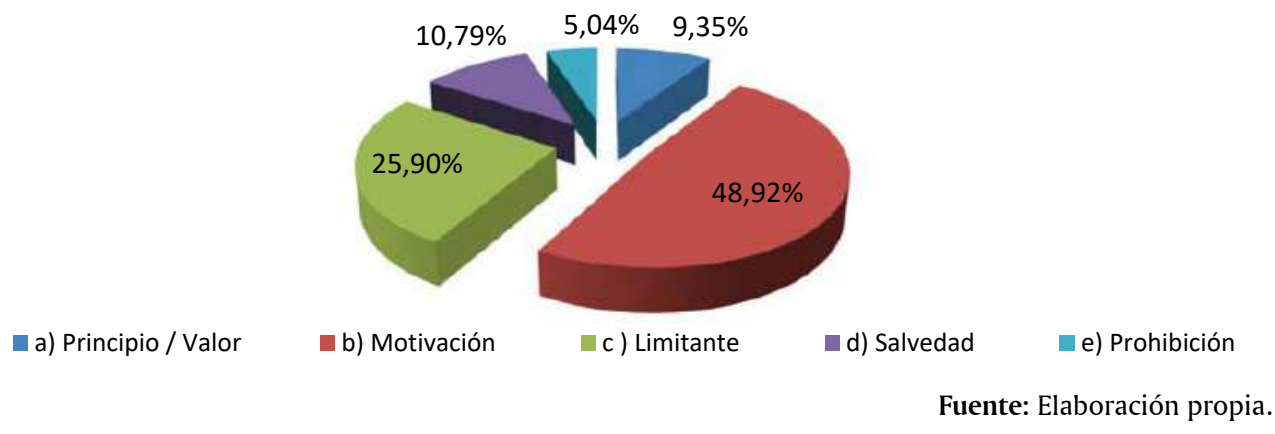


De otro lado, las expresiones analizadas, como se muestra en la Gráfica 2 , finalmente se entienden como un deber que compete en mayor parte al Estado, toda vez que la finalidad que este persigue ha de satisfacer el contenido que de ellas emana. En concordancia con ello, la Corte Constitucional en Sentencia C-128-03 refiere que "la finalidad que debe perseguirse por el agente administrativo es siempre la satisfacción del interés público".

Gráfica 2: Competencia del total de expresiones (Descriptor 2)

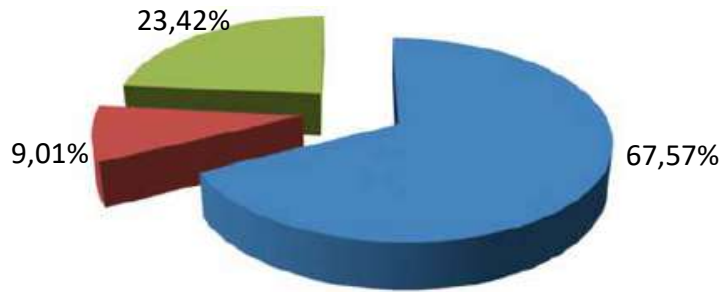

a) Deber/ Facultad/ Finalidad del Estado

b) Derecho/ Deber ciudadano

c) Ambos

Fuente: Elaboración propia.

La perspectiva que predomina en el total de las expresiones es una combinación de la económica y no económica $(46,43 \%)$, y cuando es exclusivamente la una o la otra se presenta una igualdad $(26,79 \%)$, pero si se observa separadamente en las tres segregaciones analizadas (interés público, expresiones cercanas y expresiones complementarias), en las dos primeras predomina una perspectiva que combina lo económico y no económico (55\% y 58\%), mientras que en las expresiones complementarias predomina la perspectiva económica (39\%), dado que a la expresión utilidad pública que hace parte de esta agrupación le corresponde la mayor proporción debido a que los trece países la utilizan y de estos, doce lo hacen en este sentido.

En particular se destaca frente a la expresión interés público que sólo Colombia y España tienen una perspectiva netamente económica; en Colombia dicho interés se concreta en la actividad bursátil y aseguradora y si nos remitimos a Sentencia C-860-06 de la Corte Constitucional, se destaca que la Superintendencia Financiera velará que "no se ponga en peligro ni se lesione el interés público y específicamente el interés de los inversionistas". Con lo cual queda claro que en Colombia el interés público, además de tener una perspectiva enfocada en lo económico, también privilegia el interés de un colectivo, "los inversionistas". 
Gráfica 3: Perspectivas del total de expresiones (Descriptor 3)
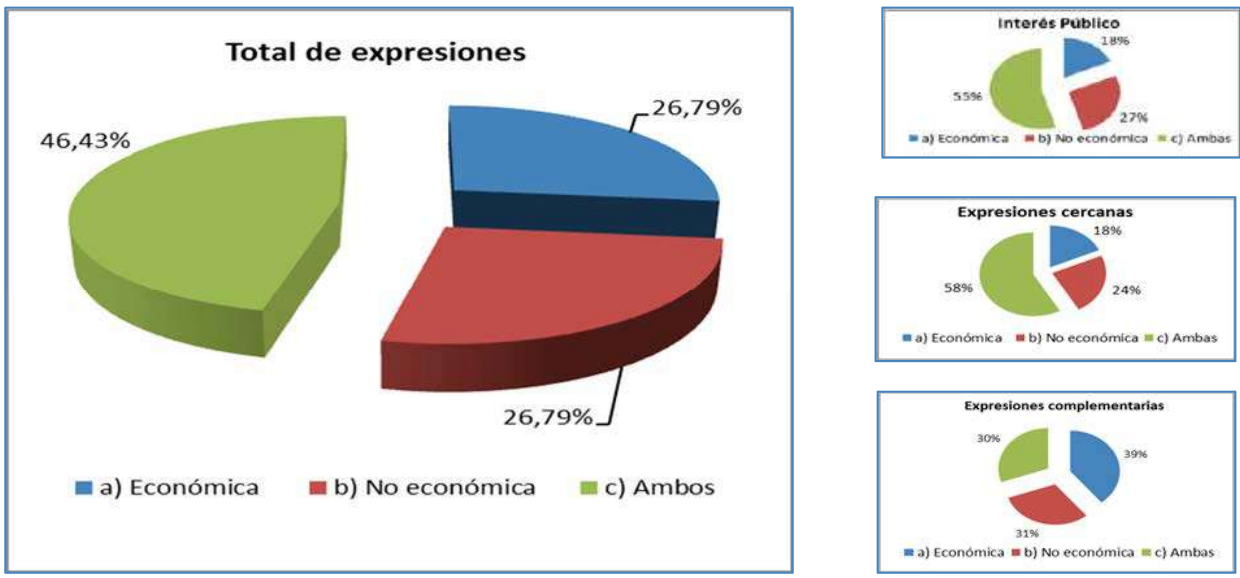

Fuente: Elaboración propia.

El carácter especial que se otorga mediante la invocación de la expresión, especialmente está dirigido a actividades con una participación del $52 \%$ y seguidamente a bienes con una $40 \%$; en menor proporción se hace para dar el carácter especial a instituciones o entidades con un $8 \%$ como se ve en la Gráfica 4.

Cuando se asigna bien sea a una actividad, entidad o bien el carácter de alguna de las expresiones, es un punto de partida para definir dicha expresión, ya que dentro del mundo de universalidades se está delimitando y asignándosele una concreción, lo cual señala efectos puntuales. Al respecto, en Sentencia C-860-06 de la Corte Constitucional, se encuentra frente a la expresión interés público, que aunque es un concepto jurídico indeterminado, "si se aplica ese concepto a unas determinadas actividades, como sucede con las actividades financiera, bursátil y aseguradora, es evidente que adquiere una concreción constitucional y jurídica especial”.

Gráfica 4: Asignación del carácter especial al total de expresiones (Descriptor 4)
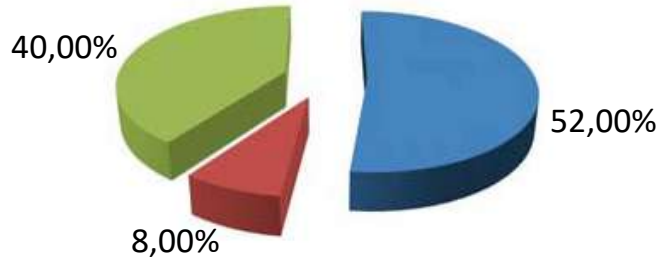

a) Actividades

b) Instituciones / Entidades

c) Bienes

Fuente: Elaboración propia. 
Pulgarín, Bustamante, Zapata. Noción de interés público en las constituciones de Iberoamérica

Finalmente, cuando se hace uso de las expresiones para referirse por ejemplo a "asuntos de interés público", "actividades de interés público", entre otros, se le está dando un uso generalizado y abstracto a la expresión, puesto que no se señala materias puntuales, ni el alcance, de tales asuntos, contrario a lo que ocurre con el descriptor anterior que concretiza para ciertas expresiones determinadas actividades, instituciones o bienes.

\section{Conclusiones}

En cuanto al descriptor 1 denominado: "La expresión interés público se utiliza como", se encontró que en el contenido de las Constituciones de Bolivia, Brasil, Chile, Colombia, Ecuador, México, Panamá, Perú y Venezuela no se utiliza de forma explícita como un principio/valor, a pesar de la frecuencia en su uso. Esto genera una aparente antinomia, dado que sí existe un plausible interés en estas constituciones, de darle un sentido estructural y vertebral a la expresión, máxime cuando se está hablando de Estados de Derecho. Adicionalmente, podría inferirse a partir de una lectura holística y desde una perspectiva integral y extensiva de las constituciones; al revisarse las expresiones cercanas y complementarias, que el interés público y social son parte axiológica del orden constitucional, pero no se enuncian así de forma expresa. De los resultados (cuantitativos = número de usos y cualitativos $=$ definición) se puede decir que el interés público en las Constituciones objeto de estudio no es un principio o valor en términos exegéticos o gramaticales, contrario a lo que ocurre con las expresiones cercanas, que sí están de forma expresa como principio cuando se refieren a los beneficios de la colectividad.

Por otro lado, la utilización del término interés público como motivación, evidenció que se utiliza precisamente para justificar y legitimar el actuar de la administración; es decir, hace las veces de conceptualizador, por el poder gramatical que tiene el término para orientar el espíritu de las regulaciones constitucionales, legales y administrativas. Lo anterior, con la singularidad que en los países en los cuales se usa expresamente, es para justificar la importancia de la contratación estatal, el papel del estado como regulador de la explotación de los recursos naturales y de los servicios públicos domiciliarios, además de utilizarse como sustento de las facultades legislativas del Congreso, entre otros. Se puede decir que, la principal causa de esto es que, el Estado debe actuar bajo el interés social y el imperio del derecho de acuerdo con sus funciones definidas desde el orden constitucional, en buscar salvaguardar a la población. Por otro lado, en cuanto a las expresiones cercanas, cuando se utilizan como motivación, se puede decir que, lo que se busca es un desarrollo integral de cada uno de los sectores económicos, sociales y políticos, debido a que por medio de estas expresiones se justifica la intervención del Estado. 
El descriptor 2 identificado como: "El interés público se entiende como" permite concluir que, tanto el término interés público como las expresiones cercanas y complementarias, son entendidas principalmente como facultad, derecho y finalidad del Estado. Lo cual, complementado con lo manifestado por Gil (2011), lleva a inferir que el Estado debe actuar como garante y principal responsable de todas las esferas de la vida en sociedad; es decir, su rol de regulador incrementa en gran medida su responsabilidad, y obliga a quienes ejerzan los cargos públicos a velar por los intereses colectivos o por decirlo de otra manera, por el bienestar general. En este sentido, el entendimiento de la expresión se enmarca un principio catalizador de las subjetividades los funcionarios públicos, a partir de un orden normativo que tiene poder vinculante y subyace al poder constituyente de la sociedad.

En el caso del descriptor 3, asociado a si el interés público incorpora una perspectiva económica, no económica o ambas, se puede concluir que, en los tres grupos empleados para clasificar los resultados (interés público, expresiones complementarias y expresiones cercanas) los términos integran las perspectivas, dependiendo el derecho o el deber que se pretende regular, y están encaminadas a salvaguardar los recursos naturales, patrimoniales y de información. Adicionalmente se utiliza en otros contextos, para catalogar y resaltar derechos fundamentales como la educación, responsabilizando al Estado de su cumplimiento y acceso para todos los individuos de la población.

El descriptor 4 hizo referencia al carácter que se le otorga a la expresión, y permite concluir que el interés público junto con las expresiones cercanas y complementarias, hacen referencia a actividades económicas que en su implementación podrían afectar significativamente a la sociedad, como por ejemplo las relacionadas con actividades financieras, bursátiles y aseguradoras, debido a que, las malas prácticas que puedan tener lugar en las organizaciones dedicadas a esto, podrían incluso, como se ha visto en sucesos históricos, generar crisis financieras significativas que afectan no solo al mercado, sino también a los pequeños inversores individuales, colectivos, sociales y solidarios. Adicional a ello, en algunas constituciones se refieren a otro tipo de actividades de las cuales se derivan los alimentos, tal vez, respondiendo a las necesidades básicas y a la importancia de salvaguardar no sólo a quienes producen estos víveres; sino también a la población que necesita de estos para la subsistencia mínima por tratarse de bienes de primera necesidad, o incluso de servicios públicos. Por otro lado, se encuentra que este término es otorgado a bienes y recursos que hacen parte del patrimonio nacional como los recursos hídricos, culturales e históricos.

Por último, en cuanto al descriptor 5 el cual enuncia usos, se concluye que, en los nueve países en los cuales se encontró la expresión de interés público y su relación con las expresiones complementarias y cercanas, se utilizan, como 
ya se mencionó, para dar una denominación o un calificativo a determinado hecho, deber o derecho regulado dentro de las Constituciones. Es decir que el uso no es meramente adjetivo o circunstancial, y por el contrario esta devenido de una fuerte carga teleológica propia de los Estados Sociales de Derecho, en los que los principios y valores buscan un orden en lo social, lo político y lo económico en pro de una ruptura epistemológica de las teorías y prácticas constitucionales precedidas de la conquista, las dictaduras y fuertes rezagos positivistas, como es el caso de la constitución colombiana de 1886.

Por otro lado, todos los conceptos analizados incorporan una teleología altruista en su esencia, a pesar de existir menciones o usos particulares a actividades o instituciones, pero en estos casos se trata es de exaltar que existen ciertas actividades, hechos, fenómenos sociales o bienes que merecen especial protección, regulación y reglamentación del estado, dado que, si se dejan a merced del mercado, la sociedad de masas o mayorías, afectarían a tal punto que reinaría la injustica social y económica. Uno de los casos se da en Colombia y España con las actividades económicas relacionadas con el sector financiero, bursátil y aseguradoras; además de las que son afines con la explotación de los recursos naturales de los países objeto de estudio. En cuanto a las instituciones, en la mayoría de los casos se hace referencia a las que pertenecen al Estado o son creadas para facilitar las labores de este.

Al igual que se le asigna el carácter de interés público a actividades, bienes o instituciones, también se evidencia similar forma de proceder con las expresiones cercanas y complementarias al interés público, con lo que se puede plantear que, si bien se delimita un poco lo que ha de considerarse parte integrante, también puede provocar confusiones en la medida en que se acude indistintamente a cualquier término que involucra un sentido social para otorgarle un orden especial.

Finalmente, se evidencia que tanto el interés público como las expresiones complementarias y similares tienen una fuerte carga principialística al interior de las constituciones, y la indeterminación de los conceptos pareciera intencional, toda vez que así, el margen de interpretación juega un papel fundamental a la hora de aplicarlos. Dentro de los contexto constitucionales actuales, los términos "principios, expresiones, derechos, valores" tienen un poder vinculante en los proyectos políticos, en tanto ese lenguaje es fuente imprescindible para comunicar lo bueno y lo malo, lo placentero y doloroso, los verdadero y lo falaz, lo justo y lo injusto, lo públicos y lo privado lo cuales en muchos casos están yuxtapuestos por el subjetivismo desenfrenado de quienes quieren pasar por alto los interés propios de la sociedad como colectivo político, social y económico organizado para hacer justicia social a través de las cartas políticas. 


\section{Referencias bibliográficas}

Baker, (2009) ¿Cuál es el significado del “interés público”? Examinando la ideología de la profesión de la contaduría pública americana. En: Gómez Villegas, Mauricio, 1977 -y Ospina Zapata, Carlos Mario. (2009). Avances interdisciplinarios para una comprensión crítica de la contabilidad. Textos paradigmáticos de las corrientes heterodoxas /Escuela de Administración y Contaduría Pública - Universidad Nacional de Colombia y Departamento de Ciencias Contables - Universidad de Antioquia. pp. 223-243.

Bernal, P. (2008) El derecho de los derechos. Universidad Externado de Colombia, Bogotá. Bobbio, N. (2006). Estado gobierno y sociedad. México DF: Fondo de cultura económica, p. 243.

Bourdieu, P. (1997). La esencia del neoliberalismo. Universidad pedagógica nacional, (35) pp. 1-5. Recuperado el 26 de octubre de 2018, Disponible en: revistas.pedagogica. edu.co/index.php/RCE/article/download/5426/4453/

Carnelutti, F. (s.f.) Cómo nace el derecho. Disponible en: https://www.academia. edu/31819289/C\%C3\%B3mo_nace_el_derecho_-_Francesco_Carnelutti.

Constitución política de Argentina. Recuperado el 20 de febrero de 2019, Disponible en: https://www.oas.org/dil/esp/Constitucion_de_la_Nacion_Argentina.pdf

Constitución política de Bolivia. Recuperado el 20 de febrero de 2019, Disponible en: http://www.mindef.gob.bo/mindef/sites/default/files/nueva_cpe_abi.pdf

Constitución política de Brasil. Recuperado el 20 de febrero de 2019 , Disponible en: https://www.wipo.int/edocs/lexdocs/laws/es/br/br117es.pdf

Constitución política de Chile. Recuperado el 20 de febrero de 2019, Disponible en: https://www.contraloria.cl/documents/451102/1887680/PDF + Constituci\%C3\%B3n + P ol\%C3\%ADtica + de + la + Rep\%C3\%BAblica/79ec65e5-9124-4c81-bbd1-0450476a338d

Constitución política de Colombia. Recuperado el 20 de febrero de 2019, Disponible en: https://www.ramajudicial.gov.co/documents/10228/1547471/CONSTITUCIONInteriores.pdf

Constitución política de Ecuador. Recuperado el 20 de febrero de 2019, Disponible en: https://www.wipo.int/edocs/lexdocs/laws/es/ec/ec030es.pdf

Constitución política de España. Recuperado el 20 de febrero de 2019, Disponible en: http://www.lamoncloa.gob.es/documents/constitucion_es1.pdf

Constitución política de México. Recuperado el 20 de febrero de 2019, Disponible en: http://www.diputados.gob.mx/LeyesBiblio/pdf/1_270818.pdf

Constitución política de Panamá. Recuperado el 20 de febrero de 2019, Disponible en: https://www.ilo.org/dyn/travail/docs/2083/CONSTITUTION.pdf

Constitución política de Paraguay. Recuperado el 20 de febrero de 2019, Disponible en: https://www.oas.org/juridico/mla/sp/pry/sp_pry-int-text-const.pdf

Constitución política de Perú. Recuperado el 20 de febrero de 2019, Disponible en: http:// www4.congreso.gob.pe/ntley/Imagenes/Constitu/Cons1993.pdf

Constitución política de Uruguay. Recuperado el 20 de febrero de 2019, Disponible en: https://www.oas.org/dil/esp/Constitucion_Uruguay.pdf

Constitución política de Venezuela. Recuperado el 20 de febrero de 2019, Disponible en: https://www.oas.org/dil/esp/constitucion_venezuela.pdf 
Pulgarín, Bustamante, Zapata. Noción de interés público en las constituciones de Iberoamérica

Correa,J. (2006). Algunas consideraciones sobre el interés público en la política y el derecho. Revista española de control externo, 8(24) pp. 135-161. Recuperado el 04 de mayo de 2018, Disponible en: https://dialnet.unirioja.es/servlet/articulo?codigo $=2254414$

Corte Constitucional de Colombia (2006). Sentencia C-860-06. Recuperado el 01 de septiembre de 2019, Disponible en: http://corteconstitucional.gov.co/ relatoria/2006/c-860-06.htm

Corte Constitucional de Colombia (2013). Sentencia C-306-13. Recuperado el 01 de septiembre 2019, Disponible en: http:/www.corteconstitucional.gov.co/ RELATORIA/2013/C-306-13.htm

De Cores, C. y Cal, J. (2007). El concepto del interés público y su incidencia en la contratación administrativa. Revista de derecho. (11) pp. 131-140.

Gil, B. (2011). La constitución de 1991: poder judicial, principio democrático y novedades institucionales. Editora: U. Javeriana

Gil, J. (2014). El interés público en contabilidad: bases para una ciencia prudencial. Conferencia llevada a cabo en la Universidad Nacional de Colombia, Sede Bogotá, Facultad de ciencias económicas. Recuperado el 12 de abril de 2018, Disponible en: https://www.youtube.com/watch?v=DJio2UItdBk.

Gómez, M. (2010). Interés público y ejercicio de la Contaduría Pública: miradas al contexto internacional y aprendizaje para la profesión en Colombia. Unimar, (54) pp. 77-91.

Huerta, C. (2007). El concepto de interés público y su función en materia de seguridad nacional. En Instituto de Investigaciones Jurídicas (Ed.), Seguridad pública. Segundo Congreso Iberoamericano de Derecho Administrativo. México: Editor. pp. 131-156.

Jiménez, R. (2012). Contabilidad entre la responsabilidad social y el interés público. Criterio Libre (17) pp. 219-234.

Lasalle, F. (1994) ¿Qué es una Constitución? Segunda edición. Santafé Bogotá: Panamericana, 1994.

López, N. (2010). El interés público: entre la ideología y el derecho. Anales de la Cátedra Francisco Suárez, (44) España. pp. 123-148.

Múnera, L. (2001). La tragedia de lo público. Trans (Bogotá) (1). pp. 224-243. Recuperado el 26 de octubre de 2018, Disponible en: www.catedras-bogota.unal.edu.co/.../La\%20 tragedia\%20de\%20lo\%20público.pdf

Pérez, A (2011). Teoría del Derecho. Madrid: Tecnos, 253p.

Quinche, Manuel (2017). Reformismo constitucional. Bogotá: Ibáñez, p. 218.

Rodríguez, C. (1994) ¿Qué es el interés público? a propósito de los "conceptos jurídicos indeterminados”. Revista de derecho público (5) pp. 61-79. Disponible en: $\quad$ https://derechopublico.uniandes.edu.co/index.php?option $=$ com content\&view $=$ article\&id $=274 \%$ ) [Consultada 20-mar-2018].

Rodríguez, X., y Muñoz, A. (2013). Sobre las transformaciones del derecho público, de León Duguit. Administración Pública, (190) Madrid. pp. 61-100.

Stiglitz, J. (2006). Cómo hacer que funcione la globalización. Bogotá: Eichborn AG, p. 433. Valencia, V. (2010) Editorial Cartas de batalla una crítica del constitucionalismo colombiano. Bogotá. Panamericana Editorial. 